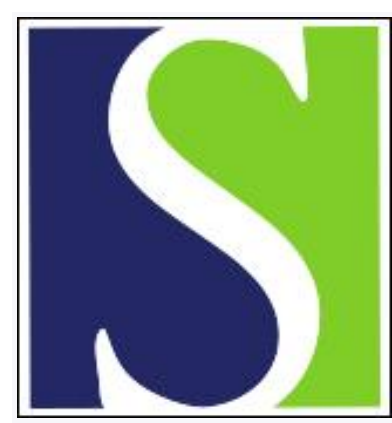

Scand J Work Environ Health 1989;15(5):353-359

https://doi.org/10.5271/sjweh.1847

Issue date: Oct 1989

Characterization of exposure to molds and actinomycetes in agricultural dusts by scanning electron microscopy, fluorescence microscopy and the culture method.

by Karlsson K, Malmberg P

Affiliation: National Institute of Occupational Health, Solna, Sweden.

This article in PubMed: www.ncbi.nlm.nih.gov/pubmed/2678431

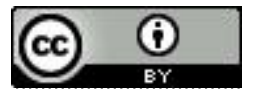




\title{
Characterization of exposure to molds and actinomycetes in agricultural dusts by scanning electron microscopy, fluorescence microscopy and the culture method
}

\author{
by Katrin Karlsson BSc, ${ }^{1}$ Per Malmberg, $\mathrm{MD}^{1}$
}

\begin{abstract}
KARLSSON K, MALMBERG P. Characterization of exposure to molds and actinomycetes in agricultural dusts by scanning electron microscopy, fluorescence microscopy and the culture method. Scand $J$ Work Environ Health 1989;15:353-359. Air samples from 79 farms with $10^{5}$ to $10^{11}$ microorganisms $/ \mathrm{m}^{3}$ were analyzed by scanning electron microscopy (SEM), fluorescence microscopy (FM), and the culture method. The total exposure to microorganisms (particularly actinomycetes) was underestimated when assessed as colony-forming units (cfu). The average cfu count was one-sixth of the total count according to SEM or FM, and the individual variability was great. This occurrence was partly explained by the aggregation of spores. Single spores accounted for 2-65\% of all spores in 35 samples. There was an average of three spores/particle, and 93 (range 67-100) \% of the spores were single or in aggregates of respirable size. Aggregation was more pronounced for actinomycetes and at high spore counts. Actinomycetes and bacteria could not be distinguished by FM. Bacteria (other than actinomycetes) were not detected by SEM, yet the total count of microorganisms was similar for FM and SEM. Most particles were spores from actinomycetes and fungi of the genera Aspergillus or Penicillium.
\end{abstract}

Key terms: air sampling, allergic alveolitis, bacteria, microorganisms, mold spores, organic dust, spores.

Allergic alveolitis is associated with exposure to high concentrations of spores of molds and actinomycetes. This relationship can be illustrated by the association with climatic and environmental factors promoting growth of microorganisms $(1,2)$ and by direct measurements (3). Exposure to very high concentrations of microorganisms may cause a toxic febrile reaction $(1,4,5,6)$ even in apparently nonsensitized subjects (organic dust toxic syndrome).

Many different methods have been used to measure exposure to microorganisms. Sampling methods include impaction on gel, use of cyclones and impingers, and collection on a filter. Microorganisms have been identified with the use of cultures or optical microscopy (7). A multistage impactor (Andersen sampler) which allows fractioning according to the aerodynamic size of the particles (8) has been extensively used in the study of agricultural dusts. Recently a method has been developed which involves dust collection on a filter followed by extraction, staining with acridine orange dye, refiltering on a black filter, and counting with fluorescence microscopy (FM) (the FM method) (9). Part of the eluted collection can be used for culturing.

All methods based on the use of cultures record particles which form colonies on the media and the temperatures used (colony forming units), but the relevant exposure measure includes spores which will not form colonies under these conditions. Earlier studies which employed the FM method to record a total count of microorganisms noted much higher total counts than

\footnotetext{
1 National Institute of Occupational Health, Solna, Sweden.
}

Reprint requests to: Dr P Malmberg, National Institute of Occupational Health, S-171 84 Solna, Sweden. the counts of colony-forming units (cfu) obtained with cultures. The variability was also great for the ratio of the cfu count to the total count $(10,11)$. This difference may be due to an aggregation of the particles or to a lack of viability.

In the present study scanning electron microscopy (SEM) was used to characterize exposure from the farming environment. This method allows direct characterization of how airborne microorganisms appear, ie, as single spores, in aggregates, or as spores bound to other particles. The size of the particles and the shape of individual spores can also be determined. Since spores of many species have a characteristic appearance, taxonomic characterization is possible to a certain degree with morphological criteria. All spores can be counted regardless of viability or aggregation.

This study comprises a comparison of the total spore count according to SEM and FM, the cfu count, the "particle count" of SEM, characterization of spore aggregates in different samples, and a description of spore types in different environments based on culturing and morphological classification with the use of SEM.

\section{Materials and methods}

One or two air samples were obtained from 79 farms in the course of three studies reported elsewhere (1, $3,12,13)$. Eighteen farms were from a random sample of farms on which the farmer had no respiratory problems (reference farms). On most of the remaining farms the farmer had reported respiratory problems. Ninety-seven samples were analyzed by the cul- 
ture method, and 42 of these same samples were also analyzed by electron microscopy. The dusts were sampled during work with different farm materials, which ranged from normal to extremely moldy. Most of the samples were of the "worst case" type and were collected for 5-15 min while the farmer was handling material which had been associated with symptoms or was believed to cause maximum exposure to mold dust. Other samples were obtained during $1-2 \mathrm{~h}$ of feeding, milking, and the distributing of bedding materials to the cows in the cow barn (background samples).

\section{Sampling}

The samples were collected with personal samplers. The farmer or the investigator carried three filter cassettes directed obliquely downwards on the chest. The cassettes were equipped with polycarbonate filters with a diameter of $37 \mathrm{~mm}$ and a pore size of $0.4 \mu \mathrm{m}$ (Nuclepore Corp, Pleasanton, California, United States). The airflow was $11 / \mathrm{min}$, and the cassettes were closedfaced.

\section{Analysis}

FM was used for enumerating the total number of spores from fungi and actinomycetes and/or bacteria. In addition, the number of cfu was counted, and viable microorganisms were characterized as described earlier (9) at the Department of Microbiology, University of Agriculture, Uppsala, or at the National Institute of

Spores $/ \mathrm{m}^{3}$ of air.

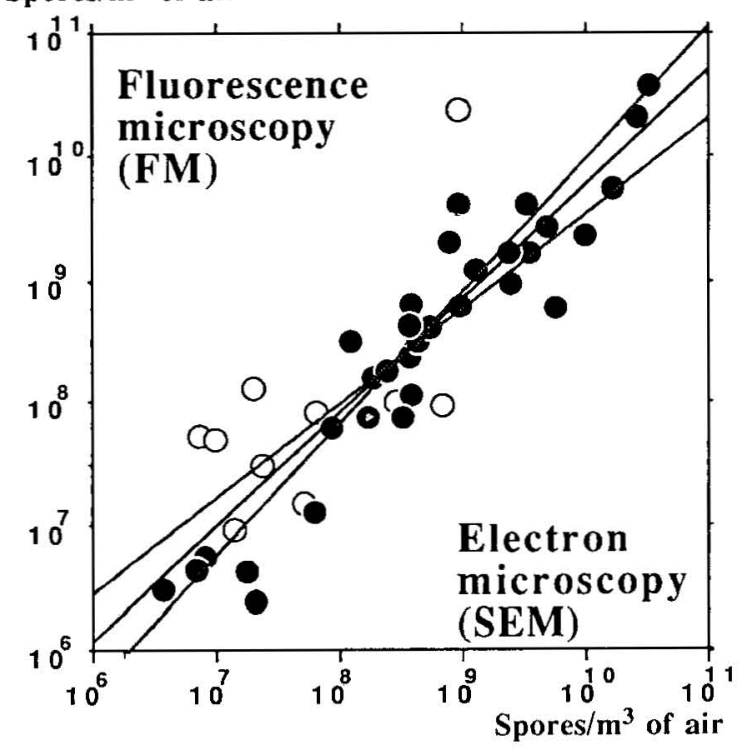

Figure 1. Total concentration of mold and actinomycete spores in air from dairy farms according to scanning electron microscopy (SEM) and FM (parallel samples). The regression line and the $95 \%$ confidence interval for the slope of the regression line are indicated. The open circles represent samples with more than $50 \%$ bacterial colonies out of the total number of colony-forming units (cfu). [Regression: ${ }^{10} \log (\mathrm{SEM})$ $\left.=0.55+0.92 \times{ }^{10} \log (F M), R^{2}=0.80\right]$
Occupational Health, Umeå. The results from the two parallel samples were averaged. The third filter was analyzed for the total number of spores of molds or actinomycetes with a scanning electron microscope at the National Institute of Occupational Health, Solna.

The enumeration and classification of microorganisms were performed within 1-2 $\mathrm{d}$ after the sampling. The spores were eluted from the filters with the use of $0.1 \%$ (weight/volume) peptone water with $0.01 \%$ Tween $80^{(\mathfrak{)})}$ (polyoxyethylene sorbitanmonooleate). One part of the suspension was used for determining viable microorganisms by the plate count method. Malt agar plates containing penicillin and streptomycin were used as a fungal medium to inhibit bacterial growth. Bacteria and actinomycetes were grown on nutrient agar with actidione to prevent fungal growth. The number of cfu was recorded after $4 \mathrm{~d}$ on plates cultured at an elevated temperature and after $7 \mathrm{~d}$ on plates cultured at room temperature $\left(21-24^{\circ} \mathrm{C}\right)$. Fungi were grown at room temperature and at $45^{\circ} \mathrm{C}$, and actinomycetes and other bacteria were grown at room temperature and at $55^{\circ} \mathrm{C}$. The highest counts of fungal, actinomycete, and bacterial colonies were added

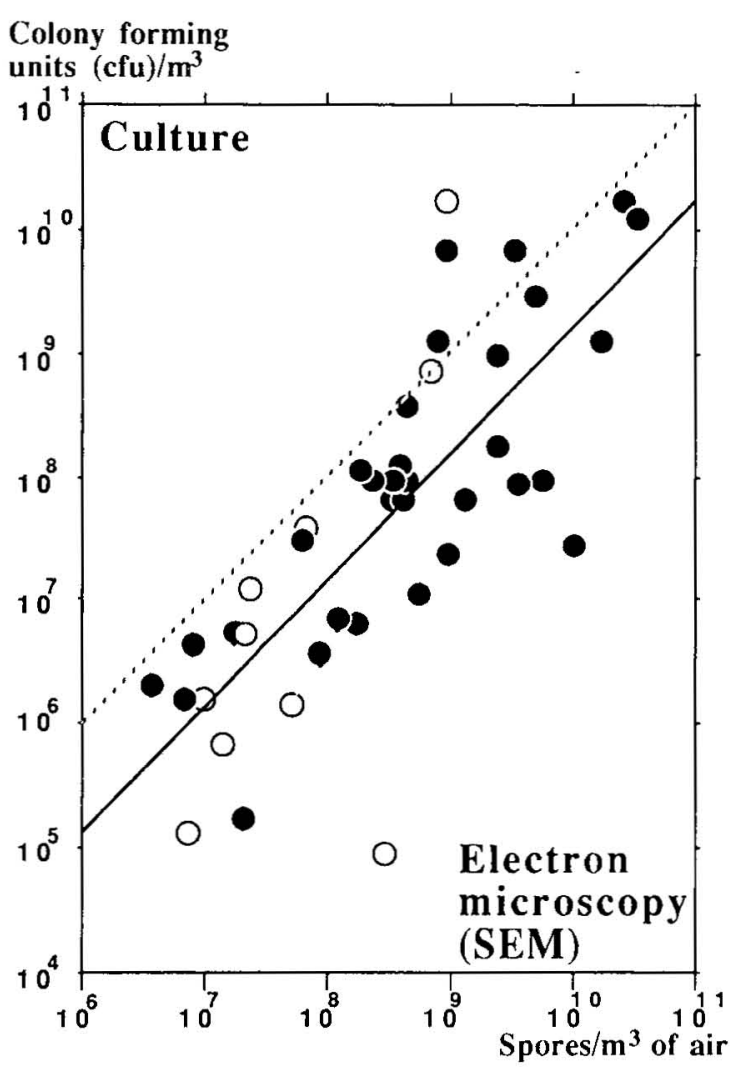

Figure 2. Total concentration of spores according to scanning electron microscopy (SEM) and the number of cfu (molds, actinomycetes and other bacteria) in the culture (parallel samples). The regression line and the line of identity (broken line) are indicated. The open circles represent samples with more than $50 \%$ bacterial colonies out of the total cfu. [Regression: ${ }^{10} \log (\mathrm{SEM})=0.939+1.018 \times{ }^{10} \log ($ culture $\left.), \mathrm{R}^{2}=0.59\right]$ 
to give the total number of cfu. Pure cultures of different fungal colonies were sent to Centraalbureau voor Schimmelcultures in Holland for identification.

Another part of the suspension was used for enumerating the total number of spores. The spores were fixed with formalin, stained with acridine orange, and filtered through a polycarbonate filter dyed with Sudan black. The total number of spores (single spores and spores in aggregates) was determined with an epifluorescence microscope from a count of 40 view fields or about 200 microorganisms per filter.

The filters were prepared for electron microscopy by gold-plating in a JEOL FC-1100 sputter. The total number of spores (single spores and spores in aggregates) was counted with a JEOL JSM-840A scanning electron microscope. Seventy to eighty viewing fields evenly distributed on a quadrant of the filter were counted at a magnification of 2000 to $6000 \times$. The most common types of fungal spores were classified, and the proportions of actinomycetes and fungal spores were calculated on the basis of morphological criteria. The procedures conformed to the recommen-

\section{Colony forming}

units $(\mathrm{cfu}) / \mathrm{m}^{3}$

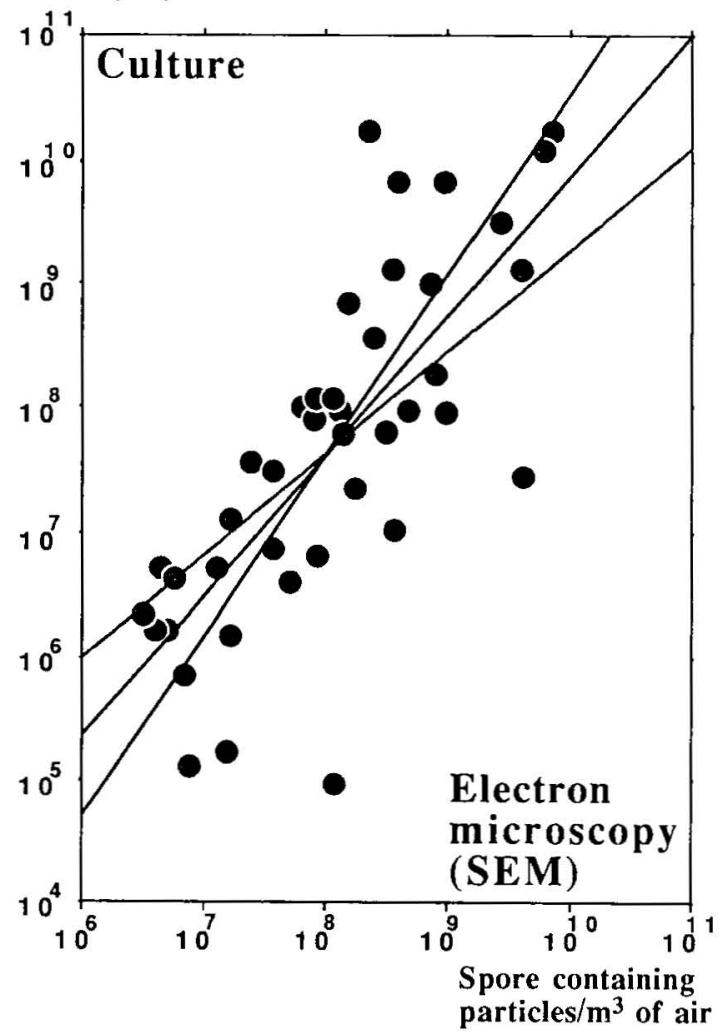

Figure 3. Number of spore-containing units (single spores or aggregates of spores) according to scanning electron microscopy (SEM) and the number of cfu in the culture (parallel samples). The regression line and the $95 \%$ confidence in terval for the regression line are given. [Regression: ${ }^{10} \mathrm{log}(\mathrm{SEM})$ $=1.417+1.129 \times{ }^{10} \mathrm{log}($ culture $\left.), R^{2}=0.59\right]$ dations of a working group on the harmonization of sampling and analyzing mold spores (14).

\section{Statistics}

When we compared paired samples, we used Student's t-test or Wilcoxon's signed rank. In addition, simple or multiple regression was used (Statview ${ }^{(\oplus)}$, Macintosh $\left.{ }^{(\beta)}\right)$. The logarithm of the spore counts was used in all the calculations.

\section{Results}

The average total spore count did not differ significantly (Student's t, Wilcoxon's signed rank) for 42 parallel samples analyzed with SEM and FM, and the slope of the regression line did not significantly deviate from 1.0 (figure 1). In one-fourth of the samples more than $50 \%$ of the total cfu consisted of bacteria (other than actinomycetes). These samples were more common at low spore concentrations (open symbols in figure 1).

The total spore count with the SEM was an average of six times higher (difference in ${ }^{10}$ logarithm $=0.79$ ) than the number of $\mathrm{cfu}$ in the cultures, but the individual variability was great (figure 2 ). The cfu count reflects spore-containing units and not individual microorganisms however. The average difference in the number of spore-containing units according to the

\section{$\%$ Actinomycetes}

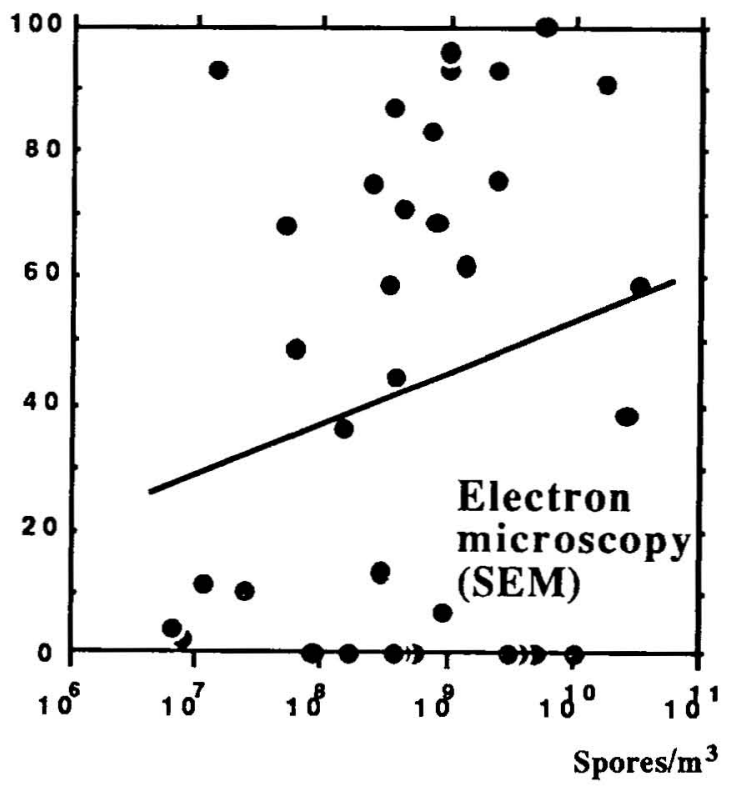

Figure 4. Percentage of actinomycete spores (out of total spores) versus total spore count according to the scanning electron microscopy (SEM). The regression line is indicated (regression not significant). 


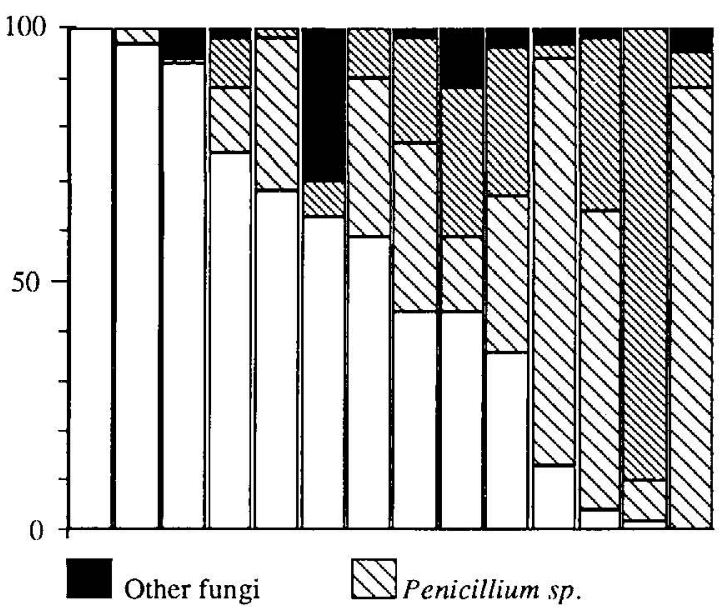

Aspergillus sp. $\square$ Actinomycetes

Figure 5. Percentage of spores from actinomycetes, Aspergillus, Penicillium, and all other molds out of the total spores in the air from 14 reference farms according to scanning electron microscopy (SEM). The samples are arranged according to the actinomycete content. On the average 120 spores were counted per sample (minimum 30 ), and 11 samples were excluded because of too low a spore content.

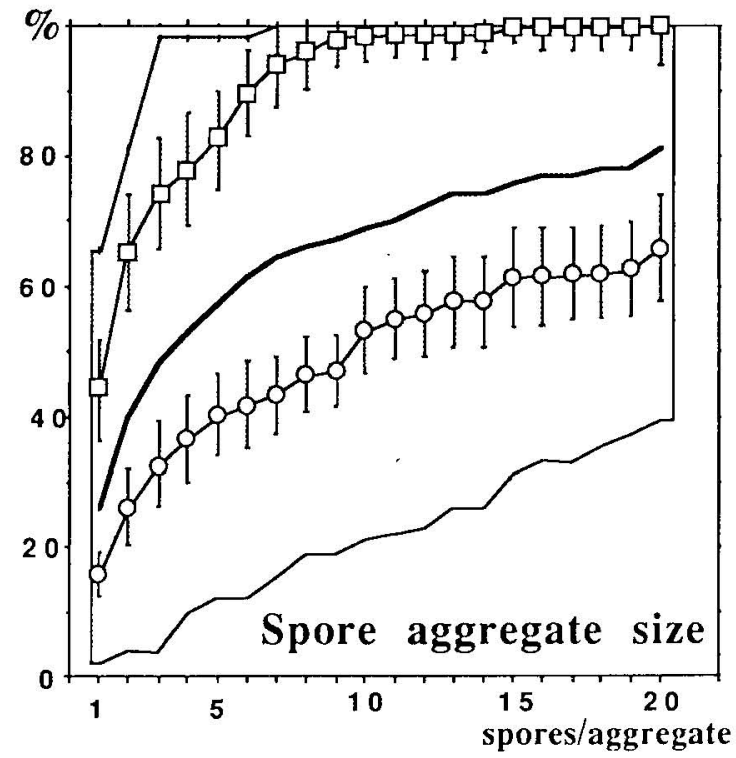

Figure 6. Cumulative distribution of spores according to the scanning electron microscopy (SEM). The percentage of spores with an aggregate size smaller than or equal to the size indicated on the abscissa is indicated on the ordinate (single spores = aggregate size one). The total aggregate size distribution of 35 samples is indicated (shadowed area). The means and the standard errors of the means of seven samples with $<50 \%$ actinomycetes and $<10^{8}$ spores $/ \mathrm{m}^{3}$ (squares) and of six samples with $>50 \%$ actinomycetes and $>10^{\circ}$ spores $\mathrm{m}^{3}$ (circles) are also indicated. The solid line represents the average of the total material, which roughly corresponds to the mean values of the samples with a low actinomycete but high spore content or the reverse.
SEM and cfu count $\left({ }^{10}\right.$ logarithm) was 0.38 , corresponding to a ratio of 2.4 (figure 3).

There was no significant relationship between the proportion of actinomycetes in the samples with SEM and the total spore count (figure 4). Air samples from 14 reference farms had a mean of 44 (SD 37) $\%$ for the actinomycetes content of the total spore count with the SEM. This value varied considerably between samples (figures 4 and 5). The percentage of colonies of actinomycetes out of the total actinomycete plus fungal cfu count was significantly lower in the cultures $(10 \%)$ than the percentage of actinomycetes out of the total fungi plus actinomycetes with the SEM ( $49 \%$, $\mathrm{N}=10, \mathrm{P}<0.05$ ).

There was an average of three spores per sporecontaining unit with the SEM, but the variation was great, as illustrated by the variability in the distribution of aggregate sizes between samples (figure 6). High actinomycete and total spore counts predisposed for aggregation. The percentage of single spores was $2-65$ $\%$ in 35 samples according to the following equation:

$\%$ single spores $=100-\%$ actinomycetes $\times 0.20-$ $7.6 \times{ }^{10} \log \left(\right.$ spores $\left./ \mathrm{m}^{3}\right), \mathrm{R}^{2}=0.54$.

Most spores were single or in aggregates with a minimum diameter of less than $10 \mu \mathrm{m}$ (mean $93 \%$, range $67-100 \%$ ).

The most common fungus species (according to the culture method) are shown in table 1. A total of approximately 50 species were detected, but most of these were found only in small numbers. There were only small differences in species composition, depending on the spore concentration (table 1) or materials which had generated the dust (table 2). Most samples were completely dominated by molds from the taxonomically related genera Aspergillus and Penicillium or by actinomycetes or by combinations of these three types of spores (reference farms, figure 5). Spores from the Aspergillus glaucus group, which were larger than the other Aspergillus spores and had characteristic surface structures, were found in $16 \%$ of the samples. Aspergillus fumigatus were smaller and had surface markings which were easily recognizable. The appearance of many Aspergillus and Penicillium species overlapped, and these taxonomically related fungi therefore could often not be differentiated from each other by SEM. Otherwise the appearance of different genera of deuteromycetes were sufficiently distinct to allow classification with SEM. A collection of SEM photos of different spores can be obtained from the authors.

\section{Discussion}

On the dairy farms on which respiratory problems had occurred, the vast majority of particles in the air samples were microorganisms such as spores of fungi and actinomycetes (figure 7). These could be present in numbers exceeding $10^{10}$ spores $/ \mathrm{m}^{3}$. This dominance 
Table 1. Fungi and actinomycetes in air samples from the examined dairy farms. (\% of samples where identified)

\begin{tabular}{|c|c|c|c|}
\hline & $\begin{array}{c}<10^{8} \\
\text { spores } / \mathrm{m}^{3} \\
(\mathrm{~N}=48) \\
(\%)\end{array}$ & $\begin{array}{c}>10^{8} \\
\text { spores } / \mathrm{m}^{3} \\
(\mathrm{~N}=45) \\
(\%)\end{array}$ & $\begin{array}{c}\text { All } \\
(\mathrm{N}=97) \\
(\%)\end{array}$ \\
\hline Zygomycetes mucoraceae (all) & 17 & $38^{*}$ & 27 \\
\hline $\begin{array}{l}\text { Rhizomucor (all) } \\
\text { Rhizomucor pusillus } \\
\text { Rhizomucor miehei } \\
\text { Absidia corymbifera } \\
\text { Mucor racemosus }\end{array}$ & $\begin{array}{c}10 \\
8 \\
\cdot \\
\cdot \\
.\end{array}$ & $\begin{array}{l}22 \\
18 \\
\cdot \\
\cdot\end{array}$ & $\begin{array}{r}15 \\
12 \\
4 \\
2 \\
2\end{array}$ \\
\hline \multicolumn{4}{|l|}{ Deuteromycetes } \\
\hline Aspergillus (all, including Eurotium, Emericella) & 75 & 80 & 76 \\
\hline $\begin{array}{l}\text { Aspergillus fumigatus } \\
\text { Eurotium herbariorum } \\
\text { Eurotium amstelodami } \\
\text { Other Aspergillus }^{\mathrm{a}}\end{array}$ & $\begin{array}{r}15 \\
10 \\
2 \\
8\end{array}$ & $\begin{array}{l}33^{*} \\
16 \\
16^{\star} \\
16\end{array}$ & $\begin{array}{r}24 \\
12 \\
8 \\
11\end{array}$ \\
\hline Penicillium (all) & 75 & 62 & 67 \\
\hline $\begin{array}{l}\text { Penicillium verrucosum } \\
\text { Penicillium brevicompactum } \\
\text { Other Penicillium }\end{array}$ & $\begin{array}{r}19 \\
4 \\
15\end{array}$ & $\begin{array}{r}27 \\
8 \\
4\end{array}$ & $\begin{array}{r}22 \\
6 \\
10\end{array}$ \\
\hline Cladosporium (all) & 29 & $9^{*}$ & 19 \\
\hline $\begin{array}{l}\text { Cladosporium cladosporioides } \\
\text { Other Cladosporium }{ }^{\mathrm{C}}\end{array}$ & $\begin{array}{r}6 \\
10\end{array}$ & $\begin{array}{l}7 \\
0\end{array}$ & $\begin{array}{l}6 \\
5\end{array}$ \\
\hline Paecilomyces ${ }^{\mathrm{d}}$ & 8 & 7 & 8 \\
\hline Other deuteromycetes & 40 & 24 & 30 \\
\hline $\begin{array}{l}\text { Trichodermae } \\
\text { Wallemia sebi } \\
\text { Acremonium }{ }^{f} \\
\text { Other deuteromycetes }\end{array}$ & $\begin{array}{r}6 \\
6 \\
4 \\
25\end{array}$ & $\begin{array}{l}9 \\
7 \\
7 \\
7\end{array}$ & $\begin{array}{r}6 \\
6 \\
5 \\
\end{array}$ \\
\hline $\begin{array}{l}\quad \text { (with }<5 \% \text { positive samples })^{9} \\
\text { Actinomycetes }\end{array}$ & $\begin{array}{l}25 \\
31\end{array}$ & $\begin{array}{c}7^{*} \\
40\end{array}$ & $\begin{array}{l}15 \\
34\end{array}$ \\
\hline
\end{tabular}

a Aspergillus candidus, A flavus, A niger, A penicilloides, A versicolor, Emericella nidulans.

- Penicillium expansum, $P$ frequentans, $P$ piceum, $P$ roqueforti, $P$ cf roseo-purpureum, $P$ rugulosum, $P$ thomii, $P$ variabile.

c Cladosporium herbarum, C macrocarpum, C sphaerospermum, $C$ tenuissimum.

¿ Paecilomyces variotii, Thermoascus crustaceus.

- Trichoderma harzianum, T pseudokoningii, $T$ viride.

i Acremonium strictum, A sclerotigenum.

9 Oidiodendron cerealis, O tenuissimum, Trichothecium roseum, Fusarium poae, Scopulariopsis brevicaulis, Verticillium lecanii, Arthrinium phaeospermum, Chrysosporium, Geomyces pannorum, Humicola fuscoatra, Microdochium bolley, Sporotrichum pruinosum. Four samples had no information on total count.

* $\mathrm{P}<0.05$.

Table 2. Fungi and actinomycetes in air sampled during the handing of different materials. ( $\%$ of samples where identified)

\begin{tabular}{|c|c|c|c|c|}
\hline & $\begin{array}{c}\text { Hay } \\
(N=26) \\
(\%)\end{array}$ & $\begin{array}{c}\text { Straw } \\
(\mathrm{N}=17) \\
(\%)\end{array}$ & $\begin{array}{c}\text { Grain } \\
(N=28) \\
(\%)\end{array}$ & $\begin{array}{c}\text { Wood- } \\
\text { chips } \\
(\mathrm{N}=7) \\
(\%)\end{array}$ \\
\hline Zygomycetes mucoraceae (all) & 23 & 59 & 25 & 29 \\
\hline Rhizomucor (all) & 15 & 24 & 18 & 14 \\
\hline Rhizomucor pusillus & 12 & 18 & 14 & 14 \\
\hline \multicolumn{5}{|l|}{ Deuteromycetes } \\
\hline Aspergillus (all) & 69 & 76 & 71 & 86 \\
\hline $\begin{array}{l}\text { Aspergillus fumigatus } \\
\text { Eurotium herbariorum } \\
\text { Eurotium amstelodami }\end{array}$ & $\begin{array}{l}19 \\
19 \\
15\end{array}$ & $\begin{array}{l}18 \\
12 \\
24\end{array}$ & $\begin{array}{r}29 \\
7 \\
0\end{array}$ & $\begin{array}{r}57 \\
14 \\
0\end{array}$ \\
\hline Penicillium (all) & 62 & 71 & 64 & 57 \\
\hline Penicillium verrucosum & 19 & 6 & 39 & 43 \\
\hline Cladosporium & 23 & 24 & 29 & 0 \\
\hline Paecilomyces & 8 & 12 & 14 & 0 \\
\hline Other deuteromycetes & 31 & 47 & 14 & 57 \\
\hline $\begin{array}{l}\text { Trichoderma } \\
\text { Wallemia sebi } \\
\text { Acremonium } \\
\text { Other deuteromycetes (with }\end{array}$ & $\begin{array}{r}4 \\
12 \\
4\end{array}$ & $\begin{array}{r}6 \\
6 \\
18\end{array}$ & $\begin{array}{l}4 \\
4 \\
4\end{array}$ & $\begin{array}{r}43 \\
0 \\
0\end{array}$ \\
\hline$<5 \%$ positive samples) & 29 & 19 & 18 & 7 \\
\hline Actinomycetes & 12 & 47 & 36 & 57 \\
\hline
\end{tabular}




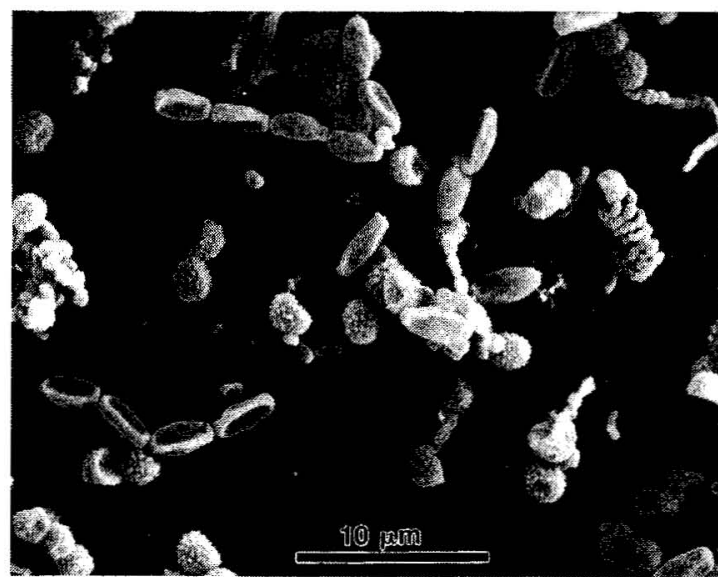

Figure 7. An example of a "worst case" air sample obtained from a farm during the handling of barley. The total spcre concentration was $3.3 \times 10^{10}$ according to the scanning electron microscopy (SEM). Practically all of the particles are spores or spore aggregates of molds and actinomycetes.

of microbial spores was also found in a random sample of farms on which the farmer had no symptoms of disease. Since these symptom-free farmers had evidence of immune stimulation and airway inflammation $(12,15)$, efforts to control and monitor exposure are warranted.

Air samples collected during work with cotton, corn, soybean, and nonmoldy grain may be dominated by particles other than microorganisms, including starch grain (16). The air samples from swine confinement buildings are dominated by large organic particles of different origin, and the microorganisms are less conspicuous. Many of the microorganisms are small, and therefore indicate the presence of either actinomycetes or bacteria, and they may stick to other organic particles (17).

In SEM a high magnification is used; therefore it is desirable to have a high density of spores on the filter. The SEM method employs a vacuum which causes collapse of most bacteria and yeasts unless special fixation techniques are used. Mold and actinomycete spores are, however, less susceptible to collapse and may be identified in samples which have not been specially prepared. The method is therefore particularly useful in environments with high exposure to spores from molds and actinomycetes, such as in dairy farming or in wood trimming departments of sawmills (18). In these environments most impaction samplers risk overloading, and sampling times must be reduced to seconds with these devices. A modification of the slit sampler method, which partly circumvents this problem, has, however, been described (19).

The FM method has been advocated as a useful tool with which to monitor spore exposure in swine confinement buildings (10). The dye may be selectively attached to microorganisms so that they are visible also in the presence of other particles.
It is not possible to distinguish between actinomycetes and other bacteria with optical microscopy or FM. On the other hand, with the routine preparation method used in the present study, bacteria (other than actinomycetes) cannot be observed in SEM. This phenomenon did not appear to influence the total spore count significantly, as judged from the comparison between SEM and FM. In one-fourth of the samples, bacteria (other than actinomycetes) constituted more than $50 \%$ of the total number of colonies formed at culture. Since the total cfu count averaged only onesixth of the total count in the SEM, this finding does not necessarily show that bacteria dominated in these samples.

The results of the present study show that spores often exist in aggregates. Preliminary reports have indicated similar findings from a limited number of dust samples $(10,11,20)$. The tendency of spores to aggregate is especially pronounced in samples with a high proportion of actinomycetes and a high total spore count. This situation helps explain part of the difference between the cfu count and the total spore count of SEM or FM, but the large variability indicates that many spores do not form colonies in the cultures due to a lack of viability, inhibition by other microorganisms, or inadequate culturing conditions.

The aggregation of spores is probably best studied by inspection of the original collection filter, either with SEM or optical microscopy, rather than on material which has been washed from the original filter holder, dyed, and collected on a second filter, as in FM.

The air samples were often dominated by a few groups, usually Aspergillus, Penicillium, or actinomycetes. It is not known if there are differences in the potential of different microorganisms to cause allergic alveolitis or toxic febrile reactions. Molds from the Aspergillus glaucus group have been implicated as important in this respect (21), and spores from this group can be distinguished from other spores by their morphological appearance in SEM.

The choice of method for collecting and evaluating microorganisms in air samples should be governed by the information desired and the environment studied. For research purposes, information from various methods can be combined. Detailed morphological classification may be obtained with cultures, but the cfu count is less informative and may seriously underestimate the total spore exposure. The proportion of actinomycetes appears to be particularly underestimated with the culture method, either due to slow growth or a high aggregating tendency. Optical microscopy and FM offer a relatively inexpensive means of estimating total exposure to microorganisms, but actinomycetes and other bacteria cannot be separated with these methods. The present study indicates that SEM is a useful tool for the study of exposure to microorganisms in dairy farming. The method allows evaluation of the total exposure to fungal and ac- 
tinomycete spores, measurement of the size and aggregation tendency of microorganisms, and partial classification of microorganisms in dust.

\section{Acknowledgments}

This study has been supported by grants $85-0508$ and 86-1229 from the National Work Environment Fund.

We would like to express our sincere thanks to $\mathrm{Dr}$ U Palmgren and Ms M Eriksson from the University of Agriculture in Uppsala for their assistance with the FM counting and the characterization of the spore types and Dr G Blomquist, National Institute of Occupational Health in Umeå, for counting FM samples. Professor S Krantz, head of the Aerosol Division at the National Institute of Occupational Health in Solna, is gratefully acknowledged for his generous help with facilities for the electron microscopy.

\section{References}

1. Malmberg P, Rask-Andersen A, Höglund S, KolmodinHedman B, Read-Guernsey J. Incidence of organic dust toxic syndrome and allergic alveolitis in Swedish farmers. Int Arch Allergy Appl Immunol 1988;87:47-54.

2. Terho EO, Heinonen OP, Lammi S. Incidence of farmer's lung leading to hospitalization and its relation to meteorological observations in Finland. Acta Med Scand 1983;213:295-8.

3. Malmberg P, Rask-Andersen A, Palmgren U, Höglund S, Kolmodin-Hedman B, Stålenheim G. Exposure to microorganisms, febrile and airway-obstructive symptoms, immune status and lung function of Swedish farmers. Scand J Work Environ Health 1985;11:287-93.

4. Emanuel DA, Wenzel FJ, Lawton BR. Pulmonary mycotoxicosis. Chest 1975;67:293-7.

5. Kotimaa MH, Husman $\mathrm{KH}$, Terho EO, Mustonen $\mathrm{MH}$. Airborne molds and actinomycetes in the work environment of farmer's lung patients in Finland. Scand J Work Environ Health 1984;10:115-9.

6. May JJ, Stallones L, Darrow D, Pratt DS. Organic dust toxicity (pulmonary mycotoxicosis) associated with silo unloading. Thorax 1986;41:919-23.

7. Gregory PH, Lacey ME. Mycological examination of dust from mouldy hay associated with Farmer's lung disease. J Gen Microbiol 1963;30:75-88.

8. Andersen AA. New sampler for the collection, sizing and enumeration of viable airborne particles. $\mathbf{J}$ Bacteriol 1958;76:471-84.

9. Palmgren U, Ström G, Blomquist G, Malmberg P. Col- lection of airborne microorganisms on Nuclepore filters, estimation and analysis - CAMNEA method. J Appl Bacteriol 1986;61:401-6.

10. Eduard W, Lacey J, Karlsson K, Palmgren U, Ström $\mathrm{G}$, Blomquist G. Evaluation of methods for enumerating microorganisms in filter samples from highly contaminated environments associated with non-infectious occupational lung disease. In: Nordic Council of Ministers. Harmonization of sampling and analysis of mould spores. Copenhagen: Nordic Council of Ministers, 1988;88:36-70.

11. Heikkilä P, Salmi T, Kotimaa M. Identification and counting of fungal spores by scanning electron microscopy. Scand J Work Environ Health 1988;14(suppl 1): 66-7.

12. Larsson K, Malmberg P, Eklund A, Belin L, Blaschke E. Exposure to microorganisms, airway inflammatory changes and immune reactions in asymptomatic dairy farmers. Int Arch Allergy Appl Immunol 1988;87: $127-33$.

13. Malmberg P, Rask-Andersen A. Natural and adaptive immune reactions to inhaled microorganisms in the lungs of farmers. Scand J Work Environ Health 1988;14(suppl 1): $68-71$.

14. Eduard W, Lacey J, Blomquist G, Malmberg P, Schneider T. Monitoring airborne microorganisms in the occupational environment. In: Nordic Council of Ministers. Harmonization of sampling and analysis of mould spores. Copenhagen: Nordic Council of Ministers, 1988;88:1-35.

15. Cormier Y, Bélanger J, Laviolette M. Persistent bronchoalveolar lymphocytosis in asymptomatic farmers. Am Rev Respir Dis 1986;133:843-7.

16. Goynes WR, Ingber BF, Palmgren MS. Microscopical comparison of cotton, corn, and soybean dusts. Environ Health Perspect 1986;66:125-33.

17. Donham KJ, Haglind P, Peterson Y, Rylander R. En vironmental and health studies in swine confinement buildings. Am J Ind Med 1986;10:289—93.

18. Eduard W, Sandven P, Johansen BV, Bruun R. Identification and quantification of mould spores by scanning electron microscopy (SEM): analysis of filter samples collected in Norwegian saw mills. In: Dodgson J, ed. Inhaled particles; VI. Oxford: Pergamon Press (in press).

19. Blomquist G, Ström G, Strömquist L-H. Sampling of high concentrations of airborne fungi. Scand $\mathrm{J}$ Work Environ Health 1984;10:109-13.

20. Eduard W, Aalen O. The effect of aggregation on the counting precision of mould spores on filters. Ann Occup Hyg 1988;32:471-9.

21. Terho EO, Lacey J. Microbiological and serological studies of farmers' lung in Finland. Clin Allergy 1979; $9: 43-52$.

Received for publication: 30 March 1989 